\title{
Ketersediaan Hara Makro Pada Beberapa Sistem Manajemen Lahan Sawah Serta Produksi Tanaman Padi (Oryza sativa L.)
}

\author{
Lilian Safitri \\ Balai Pelatihan Pertanian Jambi, Jl.Jambi - Palembang KM. 16 Desa Mestong, Kab.Muaro Jambi - \\ Provinsi Jambi \\ E-mail : Iiliansafitri800@gmail.com
}

\begin{abstract}
The purpose of this study was determint the macro nutrient content of nitrogen $(\mathrm{N})$, phosphorus $(\mathrm{P})$, and potassium $(\mathrm{K})$ in sawah with different land management systems has been conducted in Jorong air Hangat Nagari Tanjung Betung, Rao Selatan district Pasaman regency (West Sumatera Province). This study uses a comparative method by comparing traditional (land processing using hoe), transition (from tanaditional to modern), and modern management system (land processing using handtractor). In each field samples was taken through soil profiled and ring sampel with depths of $0-10,10-20,20-30,30-40$, and $40-50 \mathrm{~cm}$, respectively showed signicantly different result and influence to soil characteristic. In traditional management, organic-C content reaches 176.63 tons. ha ${ }^{-1}$, total$\mathrm{N}$ reaches 7.95 tons.ha- ${ }^{-1}, \mathrm{P}_{2} \mathrm{O}_{5}$ of 0.36 tons. ha ${ }^{-1}$, and $\mathrm{K}_{2} \mathrm{O}$ reaches 176.63 tons. ha ${ }^{-1}$. In modern management, organic- $\mathrm{C}$ decreased by $47.46 \%$ (92.79 tons.ha- $\left.{ }^{-1}\right)$, but total- $\mathrm{N}, \mathrm{P}_{2} \mathrm{O}_{5}$, and $\mathrm{K}_{2} \mathrm{O}$ increased until $9.03 \%$ (8.74 tons.ha $\left.{ }^{-1}\right), 14.28 \%\left(0.42\right.$ tons.ha $\left.^{-1}\right)$, and $20.50 \%$ (15.12 tons. ha-1), respectively which is an indication of land quality for the growing season. The result also showed the low production of rice in traditional than modern management (3.40 tons. ha ${ }^{-1}$ to 5.40 tons.ha $^{-1}$ ). To improve land quality, the addition of soil ameliorant and return of straw to sawah can be applied.
\end{abstract}

Keywords: Phosphor, potassium, management, nitrogen, sawah

\section{Abstrak}

Untuk mengetahui ketersediaan hara makro berupa nitrogen $(N)$, fosfor $(P)$, dan kalium $(K)$ pada lahan sawah dengan sistem manajemen lahan yang berbeda, maka telah dilakukan penelitian di Jorong Air Hangat Nagari Tanjung Betung Kecamatan Rao Selatan, Kabupaten Pasaman-Sumatera Barat. Penelitian ini menggunakan metode komparatif dengan membandingkan ketersediaan hara makro yang ada pada lahan sawah yang dikelola secara tradisional (mengolah dengan menggunakan tajak/cangkul), transisi (peralihan dari tradisional ke modern), dan modern (mengolah dengan menggunakan mesin traktor). Pada masing-masing lahan diambil sampel melalui profil dan ring sampel dengan kedalaman 0$10,10-20,20-30,30-40$, dan 40-50 cm menunjukan hasil yang berbeda signifikan dan mempengaruhi karakteristik tanah. Pada manajemen tradisional, kandungan $\mathrm{C}$ organik mencapai 176.63 ton/ha, N-total sebesar 7.95 ton/ha, $\mathrm{P}_{2} \mathrm{O}_{5}$ sebesar 0.36 ton/ha, dan $\mathrm{K}_{2} \mathrm{O}$ sebesar 19.43 ton/ha. Pada lahan yang dikelola secara modern, kandungan C-organik mengalami penurunan sebesar $47.46 \%$ (92.79 ton/ha) dan kandungan kalium juga mengalami penurunan sebesar $20.50 \%$ (15.12 ton/ha). Sebaliknya, kandungan $\mathrm{N}$ total mengalami peningkatan sebesar $9.03 \%\left(8.74\right.$ ton/ha) dan $\mathrm{P}_{2} \mathrm{O}_{5}$ sebesar $14.28 \%(0.42$ ton/ha) yang merupakan indikasi rendahnya kualitas lahan untuk musim tanam selanjutnya sehingga dibutuhkan input yang banyak untuk musim tanam selanjutnya. Sedangkan pada lahan transisi hanya sedikit terjadi perubahan kualitas hara tanah. Hasil penelitian juga menunjukkan rendahnya produksi tanaman padi pada lahan tradisional (3.40 ton/ha) jika dibandingkan modern ( 5.40 ton/ha) sehingga perbaikan kualitas lahan dapat dilakukan dengan penambahan pupuk kimia setengah rekomendasi pada lahan tradisional dan penambahan ameliorant pada lahan modern.

Kata Kunci: Fosfor, kalium, manajemen, nitrogen, sawah 


\section{PENDAHULUAN}

Sektor pertanian menjadi salah satu andalan bagi ketahanan pangan dan energi nasional. Kebutuhan pangan dan energi terus meningkat sejalan dengan laju pertumbuhan dan peningkatan kesejahteraan penduduk. Ketahanan pangan merupakan pilar utama stabilitas nasional, sehingga menjadi salah satu sasaran utama pembangunan pertanian yang tidak dapat ditawar-tawar. Hingga saat ini, beras masih merupakan komponen utama ketahanan pangan nasional, sehingga swasembada beras tetap menjadi indikator utama ketahanan pangan di Indonesia. Dalam pertanian berkelanjutan, ada beberapa aspek yang perlu dicapai yaitu produktivitas, efisiensi produksi, kelestarian sumberdaya dan lingkungan, serta kesejahteraan petani. Keempat sasaran tersebut dapat terwujudkan melalui dukungan inovasi teknologi dan kelembagaan. $\mathrm{Di}$ Indonesia, petani menerapkan beberapa sistem manajemen lahan dengan tujuan untuk meningkatkan produksi. Menurut Oorts et al., (2007) praktek manajemen lahan yang diterapkan petani bisa mempengaruhi sifat biokimia dan fisika tanah, termasuk lahan sawah.

Secara umum, petani di Sumatera Barat menerapkan sistem pertanian modern. Sistem pertanian modern merupakan sistem pertanian yang cenderung terfokus pada pemanfaatan teknologi pertanian yang berkembang saat ini. Menurut Acquaah (2002) pengelolaan lahan secara modern tidak hanya terfokus kepada penggunaan alat pertanian modern (misalnya penggunaan bajak pada lahan sawah) dan penggunaan air irigasi yang cukup, namun juga tidak adanya pengembalian sisa panen ke dalam tanah saat pengolahan sehingga penambahan input (seperti pupuk buatan dan pestisida) yang mempengaruhi perkembangan akar tanaman dan produksi tanaman itu sendiri.

Menurut Yoo dan Jung (2000) pupuk buatan yang diaplikasikan ke dalam tanah belum tentu dibutuhkan oleh tanaman, karena tidak semua tanaman membutuhkan unsur hara essensial yang berasal dari pupuk buatan. Kadang, unsur hara yang dibutuhkan bisa bersumber dari tanah itu sendiri. Bahkan, pupuk yang diaplikasikan dapat mempengaruhi tingkat kesuburan tanah. Walaupun ada modernisasi (pemanfaatan teknologi) pertanian yang berkembang, sebagian masyarakat di Kabupaten Pasaman masih menerapkan cara bertani tradisional, dengan alasan penerapan teknologi modern seperti penggunaan pupuk buatan yang berlebihan yang ditujukan untuk peningkatan produksi tidak mampu mempertahankan kualitas lahan mereka.

Selain itu, menggunakan bajak membutuhkan biaya yang lebih besar (sewa traktor) dalam usaha tani padi sawah. Sistem pertanian tradisional dilakukan secara sederhana. Selain telah diterapkan secara turun-temurun, serta biaya produksi juga rendah karena tidak adanya pengaplikasian pupuk buatan pada lahan selama musim tanam. Masyarakat setempat mengolah tanah dengan menggunakan "tajak" (parang berbentuk 
cangkul) hanya pada kedalaman $0-10 \mathrm{~cm}$, sisa panen yang terbawa saat mengolah tanah akan digunakan sebagai bahan pembuat pematang "pematang darurat" atau dibiarkan selama \pm 10 hari "pamasaman" (dekomposisi sisa panen) untuk dijadikan sumber bahan organik. Pembersihan tanah dengan menggunakan tajak menyebabkan tanah tidak menjadi gembur sehingga petani kesulitan dalam memindahkan bibit. Petani memiliki inisiatif menggunakan kayu runcing "martunjuk" yang membantu dalam menanam bibit. Selain itu, air irigasi hanya bersumber dari air hujan (tadah hujan). Secara teori, pertanian tradisional merupakan salah satu sistem pertanian yang mampu memelihara kualitas Iahan.

Kato (1998) menyatakan tidak intensifnya pengolahan tanah (pertanian tradisional) yang diterapkan pada lahan sawah mampu meningkatkan ketersediaan unsur silika untuk tanaman padi, biasanya ini karena adanya pengaruh dari pengembalian sisa panen (jerami) ke dalam lahan. Six et al., (2002) menyatakan sistem pertanian tradisional juga mempengaruhi akumulasi bahan organik tanah pada topsoil, namun tidak terjadi akumulasi dengan bertambahnya kedalaman tanah. Fang et al., (2012) menginformasikan penambahan pupuk ke dalam tanah seperti urea sebagai sumber nitrogen mampu meningkatkan karbon tanah sebesar 4-9\% selama musim tanam. Hal ini berbeda dengan manajemen tradisional dengan tidak adanya penambahan input kecuali pengembalian sisa panen (seperti jerami) yang memberikan pengaruh dalam menurunkan emisi metan $\left(\mathrm{CH}_{4}\right)$ pada tanah sawah.

Beberapa sistem manajemen lahan sawah tidak hanya diterapkan demi memelihara budaya dari generasi ke generasi (manajemen tradisional), ataupun ditujukan untuk peningkatan produksi (manajemen modern), namun juga akan mempengaruhi karakteristik dari tanah itu sendiri, baik berkaitan dengan ketersediaan hara ataupun keadaan fisik tanah untuk jangka panjang serta produktivitas lahan. Sehubungan dengan hal tersebut, penelitian ini bertujuan untuk melihat hubungan beberapa sistem manajemen lahan terhadap perubahan karakteristik tanah sawah.

\section{METODE}

\subsection{Lokasi Penelitian}

Penelitian berlokasi di Jorong Air Hangat Nagari Tanjung Betung Kecamatan Rao Selatan (00 28'51.58"LU dan 100 02'3.63"BT) Kabupaten PasamanSumatera Barat. Penelitian telah dilaksanakan dari bulan Februari sampai Agustus 2018. Menurut Pusat Penelitian Tanah dan Agroklimat dalam Peta Satuan Tanah dan Lahan Lembar Lubuksikaping dan Sebagian Lembar Teluk dalam Sumatera pada lembar 0716 + 0616 (1990) bahwa jenis tanah di lokasi penelitian tergolong pada ordo Inceptisol.

\subsection{Metode Penelitian}

Penelitian menggunakan metode survei dengan pendekatan komparatif (comparative approach) bertujuan untuk 
melihat pengaruh sistem manajemen lahan yang berbeda terhadap karakteristik tanah sawah. Adapun sistem manajemen lahan yang dilakukan petani setempat adalah sistem pertanian tradisional, transisi, dan modern.

\subsection{Pelaksanaan Penelitian}

\subsubsection{Survei Pendahuluan}

Survei pendahuluan dilakukan dengan tujuan untuk menentukan lokasi penelitian yang representatif sesuai dengan tujuan penelitian.

\subsubsection{Survei Utama}

\section{a. Wawancara dengan petani setempat}

Untuk mengetahui sistem pengelolaan lahan sawah dilakukan wawancara dengan petani setempat didampingi oleh interpreter (karena petani ada yang menggunakan bahasa Tapanuli Selatan). Petani mengelola lahan sawah dengan cara yang berbeda baik persiapan lahan, penanaman benih, aplikasi pupuk yang diberikan, sampai kegiatan panen, dan pemberian air irigasi. Menurut petani setempat, ada petakan sawah yang masih diolah secara tradisional dengan menggunakan "tajak" (parang dalam bentuk cangkul). Mereka mengolah lahan hanya sampai kedalaman 0-10 cm.

Pada lahan tradisional, sisa tanaman (seperti jerami) yang terbawa pada saat pengolahan lahan dikumpulkan di pinggir pematang dan dibiarkan membusuk "pamasaman" selama 7-10 hari sebelum dijadikan sumber bahan organik atau dijadikan sebagai bahan pembuat "pamatang darurat" (pematang sementara). Pengolahan dengan menggunakan tajak menyebabkan tanah tidak gembur saat pemindahan bibit, sehingga petani membutuhkan kayu runcing "martunjuk" untuk membuat lubang tanam. Selain itu, pada sistem yang masih tetap dipertahankan dari generasi ke generasi ini dilakukan untuk meminimumkan pemberian pupuk buatan. Petani menginformasikan bahwa pemberian pupuk buatan ke dalam lahan sawah dapat meningkatkan pertumbuhan gulma sehingga hasil produksi menjadi rendah dan tidak mampu memenuhi kebutuhan.

Sejak tahun 1990-an, sebagian petani setempat telah mengalihkan sistem pengolahan tanah sawah dengan menggunakan peralatan modern (seperti bajak) dan menggunakan pupuk buatan (seperti pupuk NPK). Petani mengatakan bahwa menggunakan bajak tidak hanya mempersingkat waktu pengolahan tanah namun juga memudahkan menanam bibit tanpa menggunakan "martunjuk" karena tanah telah berada dalam kondisi gembur. Para petani yang mengelola lahan secara modern cenderung memanfaatkan setiap bantuan pemerintah (misalnya pupuk buatan), sehingga produksi lebih tinggi jika dibandingkan dengan manajemen tradisional. Melihat produksi yang tinggi pada manajemen modern, sebagian petani yang mengelola lahan secara tradisional mencoba mengubah sistem pertaniannya menjadi modern (manajemen transisi).

\section{b. Sampel tanah dan metode analisis laboratorium \\ Pada luasan lahan sawah 0.25 ha diambil sampel tanah dari profil (kedalaman}


$0-10,10-20,20-30,30-40$, dan $40-50 \mathrm{~cm}$ ) untuk mengetahui perubahan karakteristik tanah dengan sistem manajemen yang berbeda (tradisional, transisi, dan modern). Pembuatan profil tanah dilakukan setelah lahan dipanen (lahan dalam keadaan kering). Sampel diambil sebanyak $500 \mathrm{~g}$ dan dikeringanginkan, serta diayak untuk keperluan analisis. Untuk analisis $\mathrm{N}$ total dilakukan dengan menggunakan metode Kjeldahl; analisis $\mathrm{C}$ organik dengan metode Walkley and Black; analisis $\mathrm{P}$ tersedia dengan metode Bray 2; dan analisis Kalium dapat dipertukarkan (K-dd) menggunakan metode leaching dengan ammonium asetat pH 7.0 (Balai Penelitian Tanah, 2005). Hasil analisis disajikan dalam bentuk grafik.

\section{c. Sampel tanaman dan metode} analisis laboratorium

Pengambilan sampel tanaman dilakukan pada saat tanaman telah mencapai masa generatif maksimum dan keseluruhan bagian tanaman diambil (dipisahkan batang dan akarnya). Bagian yang dianalisis adalah bagian atas tanaman. Adapun analisis yang dilakukan adalah analisis $\mathrm{N}$ total, unsur $\mathrm{P}$ dan $\mathrm{K}$ tanaman (Balai Penelitian Tanah, 2005).

\section{d. Produksi tanaman}

Untuk menghitung produksi, pemanenan dilakukan setelah tanaman padi menguning, kira-kira berumur \pm 100 hari, bulir padi kira-kira $85 \%$ telah masak dan biji bila ditekan terasa padat. Sampel tanaman diambil dengan cara ubinan pada masing-masing pengelolaan lahan, sebanyak 5 rumpun. Bobot kering gabah dihitung dengan menimbang gabah dari masing-masing sampel tanaman (tradisional, transisi, dan modern) untuk selanjutnya dioven selama $2 \times 24$ jam pada suhu $65^{\circ} \mathrm{C}-70^{\circ} \mathrm{C}$ (yang sebelumnya telah diukur berat basah gabah). Hasil disajikan dalam bentuk tabel.

\section{HASIL DAN PEMBAHASAN}

\subsection{Ketersediaan Hara Pada Beberapa Sistem Manajemen Lahan}

Tanah sawah dapat terbentuk dari tanah kering, tanah basah, ataupun tanah rawa yang dipengaruhi oleh bahan pembentuk tanahnya. Tanah yang disawahkan mengalami perubahan sifat tanah baik sifat mineral, kimia, fisika, dan biologi tanah. Perubahan tersebut diantaranya hancurnya suatu jenis mineral tanah oleh proses ferrolisis, terjadinya illuviasi atau eluviasi, dan translokasi partikel tanah akibat proses pelumpuran dan perubahan drainase tanah.

Mineral merupakan unsur utama penyusun tanah dan berperan penting dalam menentukan sifat kimia dan fisika tanah. Mineral merupakan salah satu indikator penting mengenai pelapukan yang telah terjadi. Peranan mineral pada tanah sawah sangat penting, selain sebagai sumber hara juga berperan dalam menentukan muatan tanah. Inceptisol merupakan tanah yang baru berkembang. Prasetyo et al., (2008) menyatakan umumnya tanah sawah di Indonesia dikelompokkan ke dalam mineral Feldspar yaitu mineral primer yang mudah melapuk (mengandung unsur $\mathrm{K}^{+}, \mathrm{Ca}^{+}$, dan $\mathrm{Na}^{+}$ yang tinggi) dan merupakan ordo Inceptisol. 
Pada saat tanah berada pada kondisi tergenang, maka terjadi proses pertukaran gas $\left(\mathrm{O}_{2}\right.$ dan $\left.\mathrm{CO}_{2}\right)$ yang ada di dalam tanah dengan udara yang ada di atmosfer. Oksigen yang ada di atmosfer diserap oleh tanaman melalui proses transpirasi dan masuk ke dalam matrik tanah, sehingga dapat dikonsumsi oleh tanaman dan organisme tanah. Pada kondisi tergenang, mikroba anaerob menjadi aktif sehingga menyebabkan bahan organik lambat melapuk. Sebagian besar $\mathrm{N}$ tanah merupakan $\mathrm{N}$ organik baik yang terdapat di dalam bahan organik tanah maupun fiksasi $\mathrm{N}$ oleh mikroba tanah dan hanya sebagian kecil (2 s.d 5\%) berupa $\mathrm{N}$ anorganik yang dapat diserap tanaman.

Aktivitas mikroba dalam merombak bahan organik mempengaruhi kandungan C organik tanah dan $\mathrm{N}$ total tanah yang berdampak pada rasio C/N tanah. Gambar 1 menunjukkan bahwa pada lahan sawah yang dikelola secara tradisional, kandungan C organik tanah mengalami peningkatan seiring dengan bertambahnya kedalaman tanah dengan kisaran antara 0.94 s.d 1.97\%. Pada kedalaman 0-10 cm, kandungan C organik mencapai $0.94 \%$ dan meningkat pada kedalaman $10-20 \mathrm{~cm}$ sebesar $0.88 \% \quad(48.35 \%)$. Hal ini disebabkan karena pengolahan lahan yang dilakukan tidak intensif sehingga bahan organik lambat terdekomposisi dan terakumulasi pada kedalaman $10-20 \mathrm{~cm}$, akibatnya C organik menurun pada kedalaman $20-30 \mathrm{~cm}$ sebesar $0.07 \%$ ($3.70 \%$ ). Pada kedalaman $30-40 \mathrm{~cm}$ dan $40-$ $50 \mathrm{~cm}$, terjadi peningkatan kandungan $\mathrm{C}$ organik masing-masing sebesar $0.06 \%$ (3.07\%) dan 0.02\% (1.01\%). Menurut Liu et al., (2006) sistem pengelolaan lahan yang berbeda pada tanah sawah juga merupakan salah satu faktor yang mempengaruhi distribusi $\mathrm{C}$ organik akibat dari hasil dekomposisi bahan organik yang tersedia.

Pada manajemen tradisional, kandungan $\mathrm{N}$ total pada kedalaman 0-10 cm sekitar $0.14 \%$ dan meningkat pada kedalaman $10-20 \mathrm{~cm}$ sebesar $0.02 \%$ (12.5\%). Pengolahan lahan yang tidak intensif mempengaruhi akumulasi bahan organik pada kedalaman $10-20 \mathrm{~cm}$ serta sedikitnya penggenangan menyebabkan proses mineralisasi meningkat sehingga meningkatkan rasio $\mathrm{C} / \mathrm{N}$ sebesar 5.05 . Hal ini berakibat pada rendahnya $\mathrm{N}$ total pada kedalaman $20-30 \mathrm{~cm}, 30-40 \mathrm{~cm}$, dan $40-50$ $\mathrm{cm}$.

Pada lahan sawah transisi, kandungan $\mathrm{C}$ organik tanah (kedalaman 0$10 \mathrm{~cm}$ ) mencapai $0.14 \%$ dan meningkat pada kedalaman $10-20 \mathrm{~cm}$ sebesar $0.27 \%$ (23.68\%). Peningkatan terjadi karena selain pengaplikasian pupuk $\mathrm{N}$ akibat peralihan dari manajemen tradisional, keadaan tergenang juga mempengaruhi dekomposisi bahan organik (menjadi lambat). Pada kedalaman 20- $30 \mathrm{~cm}$ bahwa kandungan $\mathrm{C}$ organik menurun sebesar 0.33\% (28.94\%). Hal ini disebabkan karena tingginya jumlah pori makro, pertukaran udara di dalam tanah menjadi meningkat dan bahan organik terdekomposisi lebih cepat (belum terbentuk lapisan tapak bajak) yang mengakibatkan terjadinya akumulasi bahan 
organik dengan bertambahnya kedalaman tanah. Akibat dari peralihan manajemen tradisional menjadi modern, petani mengaplikasikan pupuk buatan sebanyak $250 \mathrm{~kg}$ Urea/ha berdampak pada meningkatnya kandungan $\mathrm{N}$ total pada kedalaman 0-10 cm mencapai $0.20 \%$.



Gambar 1.

Pengaruh manajemen lahan terhadap rasio $\mathrm{C} / \mathrm{N}$ pada lahan sawah

\section{Dengan kandungan C organik} sebesar $0.89 \%$ mempengaruhi rasio $\mathrm{C} / \mathrm{N}$ (4.42). Hal ini berdampak terhadap distribusi kandungan $\mathrm{N}$ total tanah dengan bertambahnya kedalaman menjadi rendah. Gambar 1 juga menunjukkan perbedaan manajemen lahan mempengaruhi kandungan $\mathrm{C}$ organik pada lahan sawah yang dikelola secara modern. Pada kedalaman $0-10 \mathrm{~cm}, \mathrm{C}$ organik tanah hanya $0.40 \%$ dan menurun pada kedalaman 10 $20 \mathrm{~cm}$ sebesar $0.14 \% \quad(-15 \%)$. Hal ini disebabkan karena aplikasi pupuk buatan yang diberikan mempengaruhi proses mineralisasi dari nitrogen sehingga mempengaruhi kandungan $\mathrm{C}$ organik pada tanah sawah (lapisan olah). Pada kedalaman $20-30 \mathrm{~cm}$ dan 30-40 cm bahwa kandungan $\mathrm{C}$ organik meningkat masingmasing sebesar $0.87 \% \quad(71.90 \%)$ dan $0.27 \%$ (18.24\%). Hal ini mengindikasikan bahwa proses penggenangan pada lahan sawah mempengaruhi aerase dan drainase sehingga penguraian bahan organik menjadi meningkat oleh mikroba tanah.

Kandungan $\mathrm{N}$ total tanah lebih tinggi pada manajemen modern dibandingkan dengan manajemen tradisional $(0-10 \mathrm{~cm})$ yaitu $0.19 \%$. Pada kedalaman $10-20 \mathrm{~cm}$ kandungan $\mathrm{N}$ total menurun sebesar $0.03 \%$ $(-15.78 \%)$. Proses penggenangan mempercepat proses pelapukan bahan organik tanah (rasio $\mathrm{C} / \mathrm{N}$ adalah 2.16). Akumulasi bahan organik meningkat pada kedalaman $30-40 \mathrm{~cm}$ sebesar $0.04 \%$ (17.64\%). Tanah dengan kandungan liat yang tinggi berkorelasi positif dengan peningkatan kandungan $\mathrm{N}$ total tanah. Hal ini juga ditandai dengan meningkatnya rasio $\mathrm{C} / \mathrm{N}$ pada lapisan $30-40 \mathrm{~cm}$ mencapai 8.76.

Menurut petani setempat bahwa adanya perbedaan jumlah pupuk buatan dan pupuk organik dari masing-masing daerah (karena kebiasaan turun-temurun) yang diaplikasikan pada manajemen tradisional dan modern. Kyuma (2004) menyatakan pengaplikasian pupuk terutama pupuk $\mathrm{N}$ pada lahan sawah dalam jumlah tertentu mempengaruhi ketersediaan hara tanah terutama rasio $\mathrm{C} / \mathrm{N}$ tanah. Pemupukan $\mathrm{N}$ yang diberikan ke dalam tanah baik dalam bentuk pupuk buatan dan pupuk organik mempengaruhi 
ketersediaan $\mathrm{N}$ total. Pupuk N mempengaruhi perkembangan akar tanaman padi dan meningkatkan proses mineralisasi $\mathrm{N}$ tanah. Pada saat nitrogen yang diaplikasikan dalam jumlah yang berlebihan maka akar mengalami overdosis sehingga menurunkan rasio $\mathrm{C} / \mathrm{N}$. Dampaknya, bahan organik lebih cepat terdekomposisi sehingga kandungan $\mathrm{N}$ di dalam tanah mengalami peningkatan.

Selain itu, unsur $P$ juga perlu dipertimbangkan pada tanah sawah. Menurut Kyuma (2004) bahwa sumber unsur $\mathrm{P}$ pada tanah sawah tidak hanya berasal dari air irigasi (pada sawah beririgasi), namun juga dipengaruhi oleh kandungan $\mathrm{P}$ total yang berasal dari bahan induk tanah. Jumlah $\mathrm{P}$ total di dalam tanah hampir sama, yang membedakan adalah kemampuan tanah dalam menyediakan unsur $P$ agar tersedia untuk tanaman. Perbedaan bahan induk dan keadaan tanah sawah yang cenderung tergenang mempengaruhi ketersediaan unsur $P$ dibandingkan lahan kering.

Gambar 2 juga menginformasikan pada lahan sawah yang dikelola secara transisi, terjadi peningkatan kandungan $P$ tersedia sebesar 0.61 ppm (1.97\%). Hal ini disebabkan karena pengaruh pemberian pupuk $P$ pada lahan sawah selama musim tanam akibatnya terjadi akumulasi $P$ tersedia pada kedalaman 10-20 cm sebesar 5.01 ppm (14.03\%). Selama proses penggenangan, $\mathrm{P}$ tersedia dalam jumlah yang cukup untuk diambil tanaman dalam menunjang pertumbuhannya sehingga ketersediaan unsur $P$ di dalam tanah menurun pada kedalaman 20-30, 3040, dan 40-50 cm. Selain itu, pemberian pupuk $\mathrm{P}$ selama musim tanam secara terus-menerus mampu meningkatkan ketersediaan $P$ (dengan manajemen modern pada kedalaman 0-10 cm). Kandungan $\mathrm{P}$ tersedia mencapai 34.34 ppm dan meningkat sampai 35.46 ppm (3.15\%). Menurut Zhang et al., (2003) bahwa tingginya pupuk buatan (pupuk P) yang diberikan pada tanah meningkatkan ketersediaan $\mathrm{P}$ pada profil tanah.

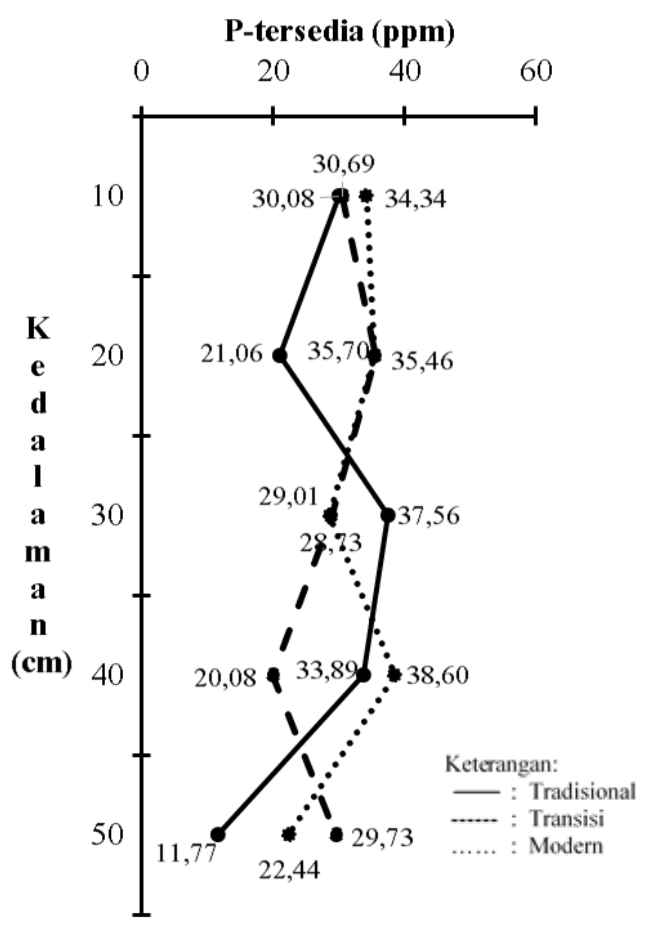

Gambar 2.

Pengaruh manajemen lahan terhadap ketersediaan unsur $\mathrm{P}$ pada lahan sawah

Menurut Furukawa (1978 cit Kyuma, 2004) menyatakan ketersediaan unsur $P$ pada tanah dalam kondisi tergenang dipengaruhi oleh (a) reduksi $\mathrm{Fe}^{3+-} \mathrm{P}$ menjadi $\mathrm{Fe}^{2+}-\mathrm{P}$, (b) tingginya kelarutan Fe-P dan Al$\mathrm{P}$ pada $\mathrm{pH}$ tanah yang netral, dan (c) mineralisasi dari fosfat organik. Hal yang 
sama juga terjadi pada lahan sawah yang dikelola secara modern, dimana ketersediaan $\mathrm{P}$ lebih tinggi pada kedalaman 0-10 cm (44.78 ppm) dan menurun dengan bertambahnya kedalaman tanah. Tingginya ketersediaan $P$ pada kedalaman $0-10 \mathrm{~cm}$ berasal dari sumbangan $P$ dari bahan induk tanah dan dari pupuk buatan yang diberikan oleh petani selama musim tanam.

Kalium merupakan hara mobil yang diserap tanaman dalam bentuk ion $\mathrm{K}^{+}$ dalam Iarutan tanah. Kalium yang terdapat dalam larutan tanah berada dalam bentuk keseimbangan $\mathrm{K}$ yang diadsorbsi liat. Penggenangan yang menghasilkan $\mathrm{Fe}^{2+}$ dan $\mathrm{Mn}^{2+}$ dalam jumlah yang besar dapat menggantikan $\mathrm{K}$ yang diadsorbsi liat sehingga $\mathrm{K}$ terlepas ke dalam larutan tanah dan tersedia bagi tanaman. Gambar 2 menunjukkan kandungan K-dd pada manajemen tradisional (kedalaman 0-10 $\mathrm{cm}$ ) lebih tinggi jika dibandingkan dengan kedalaman $10-20 \mathrm{~cm}, 20-30 \mathrm{~cm}, 30-40 \mathrm{~cm}$, dan 40-50 cm yaitu sebesar $0.41 \mathrm{me} / 100 \mathrm{~g}$. Tingginya kandungan K-dd pada lapisan atas merupakan sumbangan dari material bahan induk tanah yang kaya akan kalium (bahan Alluvium). Namun, Hardjowigeno dan Rayes (2005) mengemukakan pada tanah sawah dengan tingkat pengelolaan yang rendah, biasanya $\mathrm{K}$ cukup tersedia di dalam tanah.

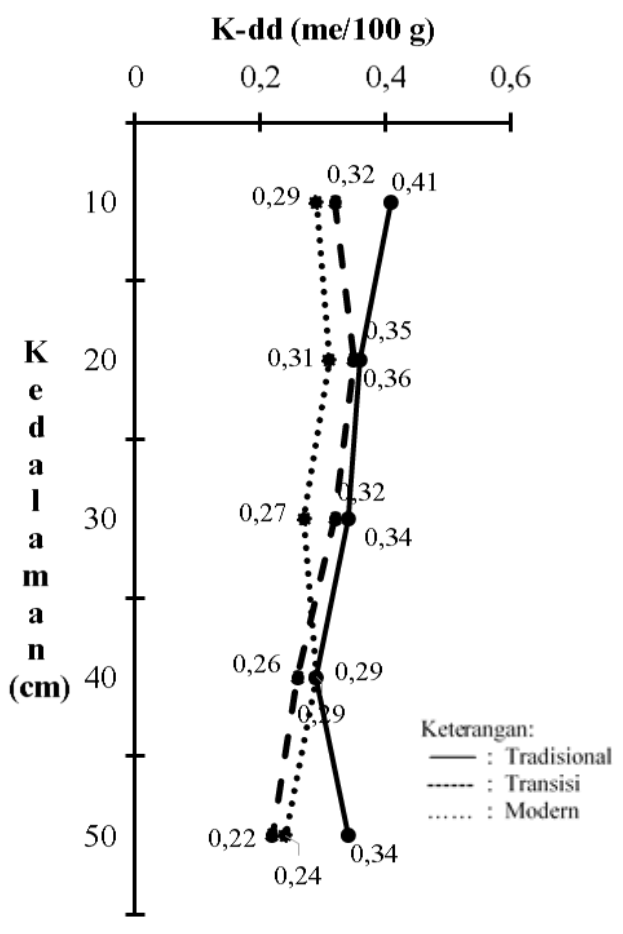

Gambar 3.

Pengaruh manajemen lahan terhadap ketersediaan unsur $\mathrm{K}$ pada lahan sawah

Pada manajemen transisi, kandungan K-dd (kedalaman 0-10 cm) lebih rendah dibandingkan pada kedalaman 10$20 \mathrm{~cm}$ yaitu dari $0.32 \mathrm{me} / 100 \mathrm{~g}$ menjadi $0.35 \mathrm{me} / 100 \mathrm{~g}$ (8.57\%). Tingginya K-dd pada lapisan olah disebabkan karena selain sumbangan dari material bahan induk tanah, juga berasal dari aplikasi pupuk buatan yang diberikan petani selama musim tanam. Hal yang sama juga terjadi pada lahan sawah yang dikelola secara modern, dimana kandungan K-dd meningkat pada kedalaman $10-20 \mathrm{~cm}$ mencapai $0.53 \mathrm{me} / 100 \mathrm{~g}$ (seperti disajikan pada Gambar 3). Proses penggenangan dapat meningkatkan ketersediaan $\mathrm{K}$ tanah. Yoshida (1965) menyatakan respon tanaman padi sawah terhadap pemupukan $\mathrm{K}$ umumnya rendah karena kebutuhan $\mathrm{K}$ 
dapat dicukupi dari cadangan mineral $\mathrm{K}$ yang berada dalam keseimbangan dengan $\mathrm{K}$ dalam larutan tanah, air irigasi dan dekomposisi bahan organik tanah.

Menurut Kyuma (2004) jika dibandingkan dengan lahan kering, ketersediaan $\mathrm{K}$ pada tanah sawah jumlahnya lebih besar karena sebagian berasal dari air irigasi. Kualitas dan kuantitas air irigasi yang diberikan mempengaruhi perkolasi air ke dalam tanah sehingga juga mempengaruhi ketersediaan kationkation yang ada di dalam tanah. Tisdale (1985 cit Rosmarkam dan Yuwono, 2002) mengemukakan kekurangan $K$ menyebabkan produksi merosot, walaupun sering tidak memperlihatkan gejala defisiensi yang disebut dengan lapar tersembunyi (hidden hunger).

\subsection{Produktivitas Tanah Sawah Pada Beberapa Sistem Manajemen Lahan}

Ketersediaan hara mempengaruhi produksi tanaman, terutama pada tanah sawah. Produksi padi pada manajemen tradisional lebih rendah yaitu 3.40 ton/ha dibandingkan manajemen modern yang dapat mencapai 5.40 ton/ha. Hal ini sangat berkaitan erat dengan jumlah hara yang bisa diambil tanaman untuk pertumbuhan dan perkembangannya. Tabel 1 menunjukkan perbedaan sistem manajemen lahan mempengaruhi serapan hara tanaman pada tanah sawah dimana jumlah $\mathrm{N}$ total yang diserap tanaman pada manajemen tradisional lebih rendah dibandingkan manajemen modern yaitu $272.75 \mathrm{~kg} / \mathrm{ha}$ meningkat sebesar 300.59 $\mathrm{kg} / \mathrm{ha}(9.26 \%)$ sehingga terjadi peningkatan jumlah produksi.

Menurut Li et al., (2003a); Pottoff et al.,(2005) bahwa aplikasi pupuk $\mathrm{N}$ yang tinggi menyebabkan produksi juga meningkat. Selain itu, juga terjadi peningkatan serapan $P$ dengan manajemen modern dibandingkan manajemen tradisional yaitu dari $12.68 \mathrm{~kg} /$ ha meningkat menjadi $15.56 \mathrm{~kg} / \mathrm{ha}$ (18.51\%). Hal ini disebabkan karena tingginya pupuk $P$ (seperti Phonska) yang diberikan pada manajemen modern jika dibandingkan manajemen tradisional (yang tidak diberikan pupuk buatan). Walaupun terjadi peningkatan serapan $\mathrm{N}$ dan $\mathrm{P}$ yang diambil tanaman pada lahan yang dikelola secara modern, namun serapan $\mathrm{K}$ lebih tinggi pada manajemen tradisional dibandingkan modern yaitu menurun $24.14 \%$.

Tabel 1. Pengaruh manajemen lahan terhadap produksi tanaman

\begin{tabular}{|c|c|c|c|c|c|}
\hline Manajemen & C-Total & $\frac{\text { N-Total }}{(\mathrm{Kg}}$ & P-Total & K-Total & $\begin{array}{l}\text { Produksi } \\
\text { (ton/ha) }\end{array}$ \\
\hline Tradisional & 4057.12 & 272.84 & 12.67 & 55.92 & 3.40 \\
\hline Transisi & 3910.72 & 272.33 & 17.86 & 50.03 & 4.20 \\
\hline Modern & 3249.06 & 300.56 & 15.56 & 42.41 & 5.40 \\
\hline
\end{tabular}

Keterangan: Hasil analisis laboratorium

Dari Tabel 1 juga terlihat bahwa produksi tanaman ditentukan oleh ketersediaan unsur $\mathrm{P}$ di dalam tanah (hukum Minimum Liebig). Rendahnya ketersediaan unsur $P$ tidak hanya disebabkan karena pengaruh dari 
pemupukan namun juga asal bahan induk pembentuk tanah sawah pada lokasi penelitian.

Tabel 1 menginformasikan bahwa $\mathrm{C}$ total tanaman menurun pada lahan yang dikelola secara modern dibandingkan tradisional dimana menurun dari 4057.12 $\mathrm{kg} \mathrm{C}$ total/ha menjadi $3249.06 \mathrm{~kg} \mathrm{C}$ total/ha. $\mathrm{Hal}$ ini mengakibatkan rasio $\mathrm{C} / \mathrm{N}$ lebih tinggi pada manajemen tradisional dibandingkan manajemen modern. Tingginya $\mathrm{C}$ total pada manajemen tradisional, selain tingginya hara yang berasal dari material bahan induk yang tersedia di dalam tanah juga dipengaruhi oleh rendahnya input $\mathrm{N}$ sehingga mineralisasi berjalan lambat. Hal ini dibuktikan dengan tingginya rasio $\mathrm{C} / \mathrm{N}$ tanaman pada manajemen tradisional mencapai 14.87 dibandingkan transisi dan modern dengan masing-masing sebesar $14.36(-3.43 \%)$ dan 10.81 (-27.30\%).

Serapan $P$ yang tinggi pada manajemen modern mempengaruhi rasio $\mathrm{C} / \mathrm{P}$ tanaman padi. Tabel 1 menunjukkan rasio $\mathrm{C} / \mathrm{P}$ modern lebih rendah dibandingkan rasio C/P dengan manajemen tradisional yaitu dari 320.07 menurun menjadi 208.75 (-34.77\%). Semakin rendah $\mathrm{C} / \mathrm{P}$ maka proses mineralisasi semakin cepat terjadi. Tanaman menyerap unsur $P$ dalam bentuk ion ortofosfat primer $\left(\mathrm{H}_{2} \mathrm{PO}_{4}^{-}\right)$ dan ion ortofosfat sekunder $\left(\mathrm{HPO}_{4}^{2-}\right)$. Fosfor yang diserap tanaman dalam bentuk ion anorganik cepat berubah menjadi senyawa organik. Unsur $P$ bersifat mobil dan mudah bergerak antar jaringan tanaman sehingga sangat mudah diserap oleh tanaman jika diberikan dalam jumlah yang banyak.

Menurut Morard (1970 cit Rosmarkam dan Yuwono, 2002), setelah diserap akar, unsur $\mathrm{P}$ mula-mula diangkut ke daun muda, kemudian dipindahkan ke daun yang lebih tua. Di samping itu, unsur $P$ juga banyak terdapat pada jaringan organ floem, sehingga banyak yang beranggapan bahwa unsur $P$ mempunyai fungsi translokasi unsur hara tanaman. Unsur $\mathrm{P}$ mampu mendorong pertumbuhan akar tanaman. Selain itu, juga terjadi peningkatan rasio C/K meningkat dari 72.55 menjadi 76.60 ($5.28 \%$ ), hal ini disebabkan karena peran unsur $\mathrm{K}$ dalam membantu proses fotosintesis tanaman sehingga berproduksi lebih tinggi.

\section{KESIMPULAN DAN SARAN}

\subsection{Kesimpulan}

Penerapan sistem manajemen lahan yang berbeda mempengaruhi karakteristik tanah sawah. Pada manajemen tradisional, kandungan unsur N, P, dan K, serta Corganik lebih rendah dibandingkan dengan manajemen modern yang berdampak terhadap kualitas lahan. Manajemen yang berbeda juga mempengaruhi jumlah produksi. Tanpa pemberian input dan pengolahan lahan yang tidak intensif menyebabkan produksi rendah (3.40 ton/ha) dibandingkan secara modern mencapai 5.40 ton/ha.

\subsection{Saran}

Pada sistem tradisional, diperlukan pengelolaan dengan mempertimbangkan input yang dapat diaplikasikan, misalnya 
dengan mengembalikan sisa panen (jerami)

setiap musim tanam. Pada lahan yang dikelola secara modern, maka perlu dipertimbangkan pemberian pupuk buatan serta mengaplikasikan bahan amelioran ke dalam tanah pada setiap musim tanam.

\section{DAFTAR PUSTAKA}

Acquaah G. (2002). Principles of Crop Production: Theory, Techniques, and Technology. Pearson Education, Inc., Upper Saddle River, New Jersey. 178 pp.

Balai Penelitian Tanah. (2005). Petunjuk Teknis Analisis Kimia Tanah, Tanaman, Air, dan Pupuk. Badan Penelitian dan Pengembangan Pertanian. Departemen Pertanian Bogor.

Fang, L.C., Zhou, D.N., Kou, Z.K., Zhang Z.S., Wang, J.K., dan Cai, M. (2012). Effects of Tillage and Nitrogen Fertilizers on $\mathrm{CH} 4$ and $\mathrm{CO} 2$ Emissions and Soil Organic Carbon in Paddy Fields of Central China. Plosone. Volume 7. 577-584 pp.

Hardjowigeno, S dan Rayes, S. (2005). Tanah Sawah (Karakteristik, Kondisi, dan Permasalahan Tanah Sawah di Indonesia. Bayumedia Publishing. Malang. 208 hal.

Kato, N. (1998). Evaluation of Silica Availability in Paddy Soils by Extraction Using a Phosphate Buffer Solution. Summaries of the 16th World Congress of Soil Science, Montpellier, France. 226 pp.

Kyuma, K. (2004). Paddy Soil Science. Kyoto University and Trans Pacific Press. Printed in Melbourne by BPA Print Group. 380 pp.
Li, Z.P., Zhang, T.L., Chen, B.Y., Yin, R.L., dan Shi, Y.Q. (2003). soil organic matter dynamic in a cultivation chronosequence of paddy fields in subtropical China. Acta Pedologia Sinica. 40. 344-352 pp.

Oorts, K., Merckx, R., Gre'han, E., Labreuche, J., dan Nicolardot, B. (2007). Determinants of annual fluxes of $\mathrm{CO} 2$ and $\mathrm{N}_{2} \mathrm{O}$ in long-term no tillage and conventional tillage systems in northern France. Soil Till Res 95: 133148 pp.

Prasetyo, B.H., Adiningsih, J.S., Subagyono, K., dan Simanungkalit, R.D.M. (2008). Mineralogi, Kimia, Fisika, dan Biologi Tanah Sawah. Pusat Penelitian Tanah dan Agroklimat. Bogor. 31-74 hal.

Rosmarkam, A., dan Yuwono, N.W. (2002). IImu Kesuburan Tanah. Kanisius. Yogyakarta. 224 hal.

Six J., Feller C., Denef K., Ogle S.M., dan Moraes S.J.C. (2002). Soil organic matter, biota and aggregation in temperate and tropical soils effects of no tillage. Agronomic 22: 755-775 pp.

Yoo, S.H dan Jung, Y.S. (2000). Soil management for sustainable agriculture In korea. Korea eb355. 113 pp.

Yoshida, S. (1965). Chemical aspects of the role of silicon in physiology of the rice plant. Bulletin of the National Institute of Agricultural Science 15:1$58 \mathrm{pp}$. 